\title{
Determining the optical stability of printed laboratory substrates with wheat pulp after ageing treatment
}

\author{
Irena Bates, Katja Petric Maretić, Ivana Plazonić, Valentina Radić Seleš, Maja Rudolf \\ University of Zagreb, Faculty of Graphic Arts, 10000, Zagreb, Croatia \\ e-mail: katja.petric.maretic@grf.hr
}

\begin{abstract}
The use of recovered paper in the paper and board industry worldwide has increased in the last decade. The recycling process affects several properties of the paper, so recovered pulp needs to be enriched with a certain amount of virgin fibre to increase the strength and quality of the paper, and thus the quality of the print. Since the cellulose-based printing substrates are sensitive to photolytic damage caused by exposure to light and high temperature, the focus of the research was to evaluate the stability of digital UV inkjet prints on laboratory substrates with wheat pulp. Assessment of the optical stability of laboratory substrates and prints made on them after ageing treatment was based on the reflectance spectra measurements before and after artificial ageing. In order to observe the optical changes that occur in cellulose printing substrates, unprinted and digital printed substrates, were artificially aged according to standard ASTM D 6789-02. The test chamber emits visible and near ultraviolet electromagnetic radiation in range from $290 \mathrm{~nm}$ to $800 \mathrm{~nm}$. With the deterioration of the optical stability of unprinted and digital printed substrates, it was observed through the reflectance spectra $(R)$ and the Euclidean colour difference $\left(\Delta \mathrm{E}_{00}{ }^{*}\right)$ that the highest colour degradation of all analysed samples, occurs in the first 48 hours of artificial ageing. The results of this analysis confirm that the addition of wheat pulp in paper pulp provides better optical stability of unprinted and digital printed laboratory substrates.
\end{abstract}

Keywords: Artificial ageing, Digital printing, Optical stability, Wheat pulp

\section{Introduction}

Since paper substrates have been traditionally produced from wood-derived cellulose fibres, the consumption of raw wood materials increased significantly but also led to a global awareness of the possibility of forest exploitation and the importance of reusing post-consumer wastepaper as a source of cellulose fibre $[1,2]$.

Recycling process is an old technology, that has become commercially popular since Matthias Koops established the Neckinger mill in 1826 for white paper production from printed wastepaper. At the time, there were several studies examining the impact of the recycling process on paper properties. Nowadays it is considered that the recycling process reduces the fibre swelling capability, and thus the flexibility of fibres [3].

In the last decade, the use of recycled paper in the paper and board industry has increased worldwide. Recovered paper accounts for around $50 \%$ of the total production of paper fibres used worldwide. Utilization rates of recovered paper substrates varies widely, depending on the desired quality and final purpose. Paper production cannot be based only on recovered paper, because it cannot be used effectively in all paper grades, nor can be used indefinitely. Therefore, during paper production pulp from recycled fibres needs 
to be enriched with a certain amount of virgin fibres in order to increase the strength (wood cellulose fibres decay with each recycling process) and the quality of the paper [4].

The utilization of non-wood fibres for papermaking production is the most viable economically and environmental solution that fits the European Union Directive on Environmental Protection, which aims to reduce the consumption of wood pulp in paper and cardboard production and substitute them with alternative plant biomass [5].

Fibre isolated from annual crop residues is a potential raw material for the pulp and paper industry due to many advantages of straw as a source of fibre; it is economical, obtained in abundant quantities and renewable [6]. On the other hand, there are still some shortcomings related to: fibre supply (fibre sources are harvested in a short period of time and are extremely voluminous, so large warehouses are needed, they are larger than wood which increases transportation and storage costs); production (a higher proportion of silica than wood makes a conventional chemical recovery system unsuitable, while appropriate production technology is not available and may become even more expensive than equipment used for wood); the demand stage of the use of non-wood fibres for pulp and paper production (the size of actual wood-free market is unknown) $[7,8]$.

Wheat straw is a fibrous material, which is produced annually in huge quantities in European countries in a much shorter cycle of wood cultivation. Whereas cellulose fibres are a main ingredient and structural substance of any paper, it is therefore important to analyse if the change in cellulose fibres content affects the optical stability of the print [9]. From the moment of production, numerous endogenous and exogenous factors act on deterioration of the paper. In fact, its appearance and stability depend on each component of the paper. Since electromagnetic radiation, heat and moisture are the most important factors that affect the optical and mechanical stability of paper and print, today several methods are used to simulate the natural ageing process for experimental purposes. Namely, the natural ageing process is not practical to analyse due to variation in weather conditions and due to long treatment period [10].

Ageing process analysis is a complex process because the chemical and mechanical properties of paper elements and ink components change simultaneously during the ageing process. Optical stability of prints is extremely important in the printing industry because it contributes the most to the overall appearance and attractiveness of the graphic product $[11,12]$.

The main goal of this research was to determine the influence of different proportions of wheat pulp in the laboratory substrates printed with digital printing technique on optical stability during simulation of ageing. Digital printing technique is chosen because it is a novel technology that is evolving extremely fast and in some areas is competitive with all conventional techniques. The digital printing technique is predicted to grow dramatically, because it is economically more cost-effective and creates good print quality. The process of ink jet printing is a direct printing technique, where ink heads print ink droplets on paper in response to instructions from a computer $[13,14]$. The optical stability of printed laboratory substrates with straw pulp was observed based on colour degradation assessed through reflection spectra $(R)$ and Euclidean colour difference $\left(\Delta E_{00}{ }^{*}\right)$.

\section{Experimental part}

\subsection{Materials and Methods}

\subsection{Printing substrates}

Wheat straw as agricultural residue after harvesting was manually cut into $1 \mathrm{~cm}$ to 3 $\mathrm{cm}$ pieces and converted into semi-chemical pulp according to soda method [6]. Pulping conditions are presented in Table 1. 


\section{Table 1: Pulping conditions}

\begin{tabular}{|l|l|l|}
\hline $\begin{array}{l}\text { Type of } \\
\text { straw }\end{array}$ & $\begin{array}{l}\text { Pulping } \\
\text { method }\end{array}$ & Extraction conditions \\
\hline Wheat & Soda pulping & $\begin{array}{l}\text { Temperature of } 120^{\circ} \mathrm{C}, \\
\text { alkali level of } 16 \% \text { for } \\
60 \text { min, and a } 10: 1 \text { liquid } \\
\text { biomass ratio }\end{array}$ \\
\hline
\end{tabular}

Provided unbleached wheat pulp was mixed in three different proportions $(10 \%, 20 \%$ and $30 \%)$ with pulp of recycled wood fibres.
Laboratory substrates, grammage $42.5 \mathrm{~g} /$ $\mathrm{m}^{2}$, were produced by laboratory equipment Rapid-Köthen sheet former (FRANK-PTI) according to standard EN ISO 5269-2:2001. Laboratory substrate that was made only with recycled wood pulp were used as a reference sample (marked with $\mathrm{N}$ ) to compare the optical stability of substrates and prints which contain wheat pulp. Workflow of laboratory substrate production is presented in Figure 1.

\begin{tabular}{|c|c|c|}
\hline \multicolumn{2}{|c|}{$W_{\text {pulp }}, \%$} & \multirow{2}{*}{$\begin{array}{l}\text { DISINTEGRATION } \\
\longrightarrow m_{\text {pulp }}=80 \mathrm{~g}\end{array}$} \\
\hline Recycled & Wheat & \\
\hline 100 & 0 & \multirow{4}{*}{$\begin{array}{c}V_{\mathrm{H} 2 \mathrm{O}}=1.6 \mathrm{l} \\
p H=8 \\
T=45^{\circ} \mathrm{C} \\
t=20 \mathrm{~min}\end{array}$} \\
\hline 90 & 10 & \\
\hline 80 & 20 & \\
\hline \multirow[t]{6}{*}{70} & 30 & \\
\hline & & $\downarrow$ \\
\hline & & HOMOGENISATION \\
\hline & & $\begin{array}{c}V_{H 2 O}=10 l \\
p H=7.5 \\
T=45^{\circ} \mathrm{C} \\
t=5 \mathrm{~min}\end{array}$ \\
\hline & & $\downarrow$ \\
\hline & & $\begin{array}{c}\text { Laboratory substrate } \\
\text { (handsheet) } \\
42.5 \mathrm{~g} / \mathrm{m}^{2}\end{array}$ \\
\hline
\end{tabular}

Figure 1: Workflow of laboratory substrate production

\subsection{Printing of fulltone areas on laboratory substrates and commercial paper}

Laboratory made substrates and commercial paper (marked as C) used as second control sample, were printed by UV curable ink jet printer EFI Rastek H652. Fulltone areas of magenta and black ink with the resolution of $600 \mathrm{dpi} \times 600 \mathrm{dpi}$ and printing velocity of $12.10 \mathrm{~m}^{2} / \mathrm{h}$ were printed with high quality mode, 8 pass, on each substrate. During printing process, the ambient temperature was $23^{\circ} \mathrm{C}$ and relative humidity was $55 \%$.

\subsection{Artificial ageing}

Artificial ageing treatment of unprinted and UV ink jet printed substrates was performed by the standard method ASTM D 6789-02 [15] in a SunTEST XLS+ test chamber (Figure 2.) supplied with a xenon-arc lamp and a daylight filter which emits visible and near ultraviolet electromagnetic radiation in the wavelength range from $290 \mathrm{~nm}$ to $800 \mathrm{~nm}$ with a light intensity of $(765 \pm 50) \mathrm{W} / \mathrm{m}^{2}$ under elevated temperature inside the test chamber up to $39.5^{\circ} \mathrm{C}$ (Table 2.). The light from xenonarc lamp simulates natural daylight passing 
through windows on a paper surface with a light flux that is substantially higher than normal indoor conditions.
All observed unprinted and printed substrates were cut in dimensions of $20 \mathrm{~mm} \times 50 \mathrm{~mm}$ and treated with two cycles of 48 hours.

Table 2: Conditions during artificial ageing process

\begin{tabular}{|l|l|l|}
\hline Wavelength $(\mathbf{n m})$ & $290-800$ \\
\hline Light intensity (Wm-2) & $765 \pm 50$ \\
\hline Test equipment & $\begin{array}{l}\text { SunTEST XSL+, Id.No. 196 Rotronic } \\
\text { Hygrolog, Id.No. 180/2 }\end{array}$ \\
\hline Duration process (h) & 48 & 96 \\
\hline Ambient condition & $24.8^{\circ} \mathrm{C}, 54.7 \% \mathrm{RH}$ & $23.5^{\circ} \mathrm{C}, 47.4 \% \mathrm{RH}$ \\
\hline Filter & daylight & \\
\hline
\end{tabular}

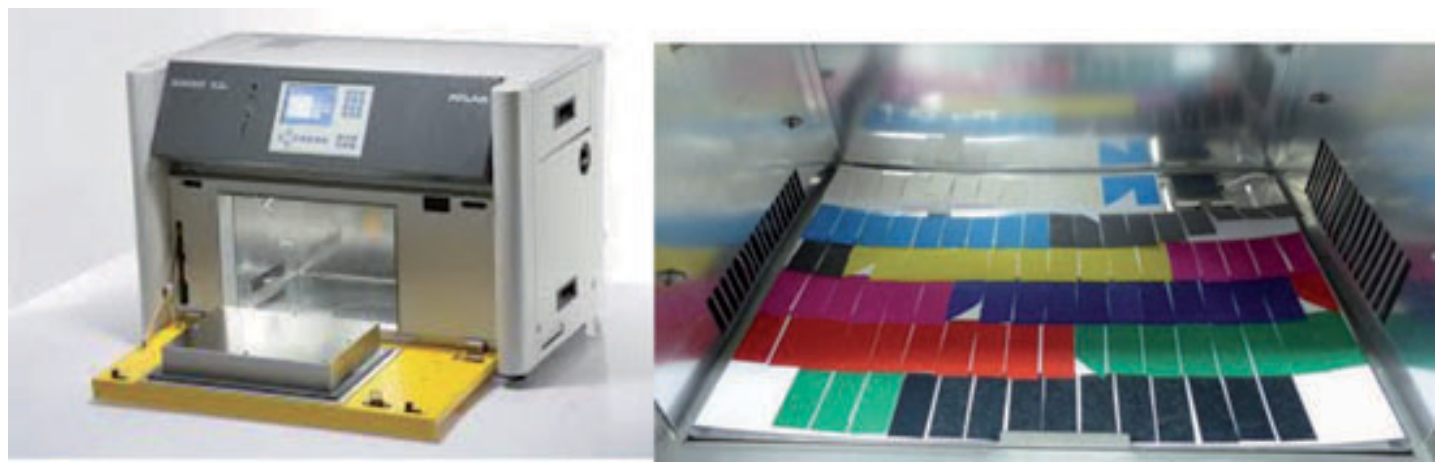

Figure 2: SUNTEST XSL+ test chamber

\subsection{Optical properties}

For determining the influence of wheat pulp in substrates on the optical stability of the unprinted and printed substrates with two inks (magenta and black), the colour degradation and reflectance changes were observed on all samples. The abbreviations of the analysed unprinted and printed substrates are described in the Table 3.
Table 3: Abbreviations used in marking samples

\begin{tabular}{|l|l|}
\hline$C$ & $\begin{array}{l}\text { commercial paper with } 100 \% \text { recycled } \\
\text { pulp }\end{array}$ \\
\hline$N$ & $\begin{array}{l}\text { laboratory paper with } 100 \% \text { recycled } \\
\text { pulp }\end{array}$ \\
\hline $1 N W$ & laboratory paper with $10 \%$ wheat pulp \\
\hline $2 N W$ & laboratory paper with $20 \%$ wheat pulp \\
\hline $3 N W$ & laboratory paper with $30 \%$ wheat pulp \\
\hline$p$. & printed paper \\
\hline unp. & unprinted paper \\
\hline$m$. & magenta ink \\
\hline b. & black ink \\
\hline unag. & unaged paper \\
\hline ag. & artificially aged paper \\
\hline
\end{tabular}




\subsubsection{Reflectance spectra measurements}

Reflectance spectra measurements of unprinted and digital printed substrates were processed using Spectroeye, X-rite spectrophotometer with standard illuminate D50 and $2^{\circ}$ observer, in the interval of the wavelengths from $400 \mathrm{~nm}$ to $700 \mathrm{~nm}$ for every $10 \mathrm{~nm}$. Reflectance values $(\mathrm{R})$ were determined on all substrates before and after ageing treatment. Reflectance measurements were repeated 10 times on each substrate.

\subsubsection{Euclidean difference $\left(\Delta \mathrm{E}_{00}{ }^{*}\right)$ values}

Euclidean difference $\left(\Delta \mathrm{E}_{00}{ }^{*}\right)$ values of all unprinted and printed substrates with magenta and black ink were obtained based on colorimetric CIE $\mathrm{L}^{\star} \mathrm{a}^{*} \mathrm{~b}^{*}$ values by $\mathrm{X}$-rite spectrophotometer. The following equation (1) is used to calculate the colour differences of all samples before and after artificial ageing treatment [16].
The definition of tolerance colorimetric differences $\left(\Delta \mathrm{E}_{00}{ }^{*}\right)$ are presented in Table 4 [17].

Table 4: Tolerances of Euclidean differences

\begin{tabular}{|l|l|}
\hline $\begin{array}{l}\text { Euclidean } \\
\text { difference value }\end{array}$ & Euclidean difference tolerance \\
\hline$<1$ & $\begin{array}{l}\text { Average human eye does not see the } \\
\text { difference }\end{array}$ \\
\hline $1-2$ & $\begin{array}{l}\text { Very small difference - optimal } \\
\Delta \mathrm{E}_{00}^{*}=2\end{array}$ \\
\hline $2-3$ & Moderate difference \\
\hline $3.5-5$ & Difference \\
\hline$>5$ & Great difference \\
\hline
\end{tabular}

$\Delta E_{00}{ }^{*}=\sqrt{\left(\frac{\Delta L^{\prime}}{k_{L} S_{L}}\right)^{2}+\left(\frac{\Delta C^{\prime}}{k_{C} S_{C}}\right)^{2}+\left(\frac{\Delta H^{\prime}}{k_{H} S_{H}}\right)^{2}+R_{T}\left(\frac{\Delta C^{\prime}}{k_{C} S_{C}}\right)\left(\frac{\Delta H^{\prime}}{k_{H} S_{H}}\right)}[1]$

where: $\Delta \mathrm{L}^{\prime}$ is the transformed lightness difference between sample before and after artificial ageing, $\Delta C^{\prime}$ is the transformed chroma difference between sample before and after artificial ageing, $\Delta \mathrm{H}^{\prime}$ is the transformed hue difference between sample before and after artificial ageing, $R_{T}$ is the rotation function, $k_{L}$, $k_{C} k_{H}$ are the parametric factors for variation in the experimental conditions and $S_{L}, S_{C}, S_{H}$ are the weighting functions. 


\section{Results and discussion}

\subsection{Reflectance spectra measurements}

Figures 3-4 present the experimental results of reflectance spectra measurements in the visible part of the electromagnetic spectrum before (marked as unag.) and after two cycles of artificial ageing treatment (marked as ag.48 and ag.96) for unprinted samples (marked as unp.).

From reflectance spectra presented in Figure 3 it is evident that the highest deterioration in both unprinted samples made from recycled pulp has occurred in the first 48 hours of artificial ageing $\left(\Delta \operatorname{Rmax}_{\text {(Cunp.unag. }- \text { Cunp.ag.48) }}=\right.$ $\left.13.9 \% ; \Delta \operatorname{Rmax}_{(\text {Nunp.unag. - Nunp.ag.48) }}=17.5 \%\right)$. After first cycle of artificial ageing treatment it is noticed that reflectance values drop down significantly in the blue-green part of spectrum while in the red part reflectance values slightly increase. After the second ageing cycle, the changes are negligible through the whole spectrum.

Figure 4 represents reflectance spectra of unprinted laboratory substrates with the addition of $10 \%, 20 \%$ and $30 \%$ wheat pulp after ageing treatment performed in two cycles. The obtained results show that the reflectance values of all laboratory substrates with wheat pulp decrease after artificial ageing treatment in the blue-green part of spectrum while increase in the red part of reflectance spectrum. This trend due to the treatment of ageing was also shown by control samples.

However, the highest degradation of unprinted substrates with wheat pulp occurs after first 48 hours of artificial ageing on unprinted laboratory substrate $1 \mathrm{NW}$

$\left(\Delta \operatorname{Rmax}_{(1 \mathrm{NW} \text { unp.unag.-1NWunp.ag. } 48)}=13.2 \%\right)$, while the substrates $2 \mathrm{NW}$ and $3 \mathrm{NW}$ have very little reduced values

$\left(\Delta \operatorname{Rmax}_{(2 N W u n p . u n a g .-2 N W u n p . a g .48)}=10.1 \%\right.$; $\left.\Delta \operatorname{Rmax}_{(3 N W u n p . u n a g .-3 N W u n p . a g .48)}=12.56 \%\right)$.

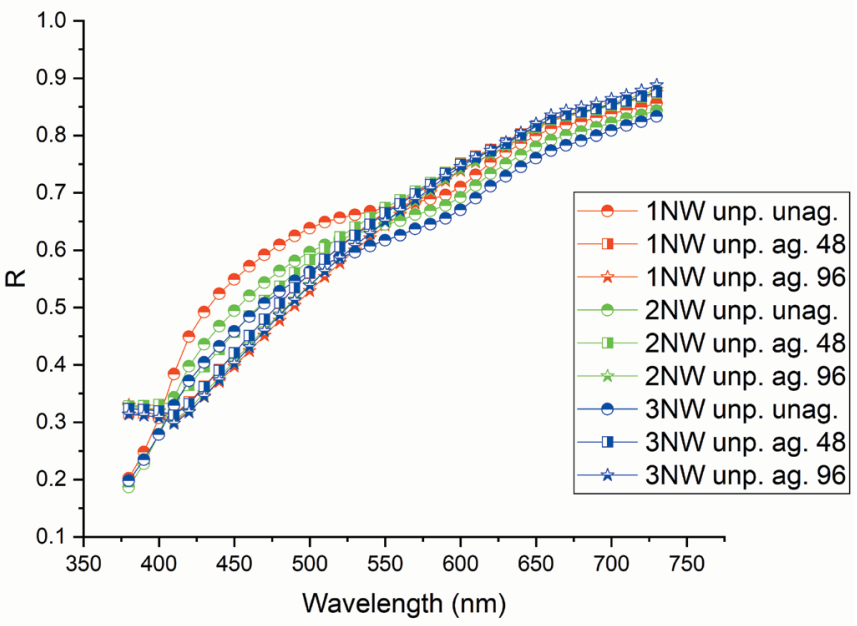

Figure 3: The influence of ageing time on reflectance spectra of unprinted control samples - commercial (C) and laboratory $(\mathrm{N})$

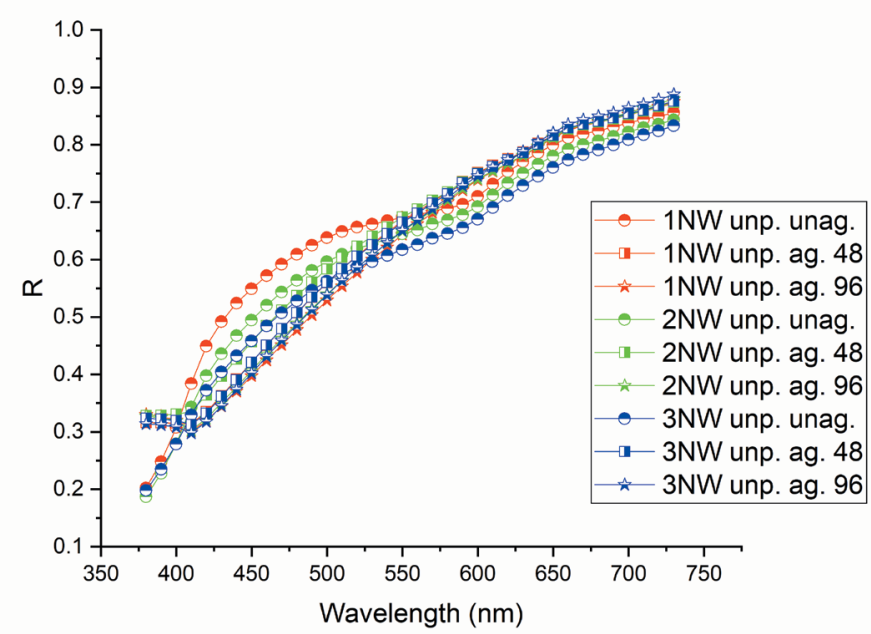

Figure 4: The influence of ageing time on reflectance spectra of unprinted laboratory substrates with wheat pulp (1NW, 2NW, 3NW)

After additional 48 hours of artificial ageing, degradation is still visible but significantly lower $\left(\Delta \mathrm{Rmax}_{(1 \mathrm{NW} \text { unp.ag. } .48 .-1 \mathrm{NWunp.ag.96)}}=3.06 \%\right.$; $\Delta \operatorname{Rmax}_{(2 \mathrm{NWunp.ag.48.}-2 \mathrm{NW} \text { unp.ag. } 96)}=5.01 \%$;

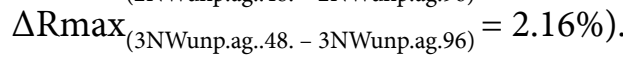

In Figures 5-6 the results of reflectance spectra measurements in the visible part of 


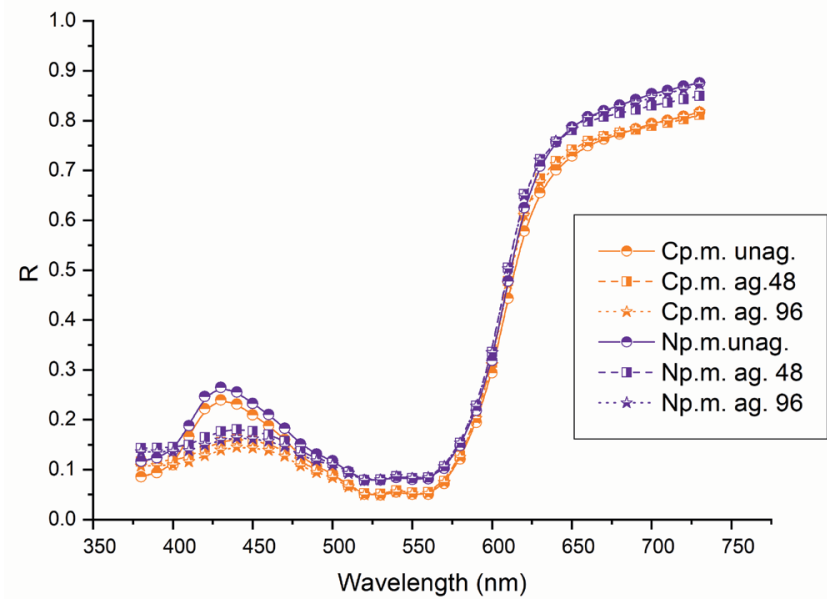

Figure 5: The influence of ageing time on reflectance spectra of control samples-commercial (C) and laboratory $(\mathrm{N})$ printed with magenta ink

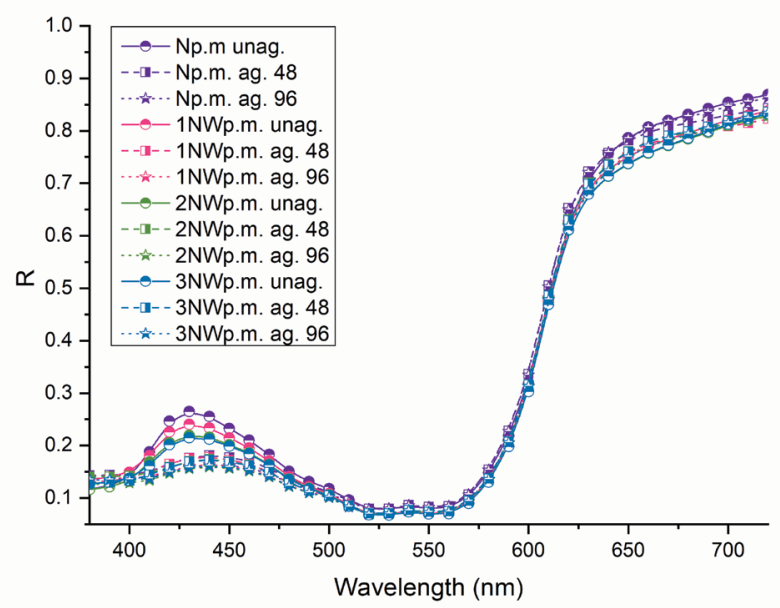

Figure 6: The influence of ageing time on reflectance spectra of magenta prints made on laboratory substrates without $(\mathrm{N})$ and with wheat pulp (1NW, 2NW, 3NW)

the electromagnetic spectrum before (marked as unag.) and after two artificial ageing treatments (named as ag. 48 and ag. 96) for printed samples with magenta ink (marked as p.m.) are presented.

Figure 5 shows that in the red part of spectrum laboratory reference sample $(\mathrm{N})$ and commercial control sample (C) are stable regardless of analysed ageing time. Only in the blue part of the spectrum some oscillations can be seen. There is a visible drop in reflectance values for magenta prints made on both samples ( $\mathrm{N}$ and $\mathrm{C}$ ) after 48 hours of artificial ageing. Change is visible after 96 hours as well, but insignificant. Namely, first 48 hours of artificial ageing have the highest impact on reflectance values of all magenta prints $\left(\Delta \operatorname{Rmax}_{(\text {Cp.m.unag. }- \text { Cp.m.ag.48) }}=\right.$ $8.43 \% ; \Delta \operatorname{Rmax}_{(\text {Np.m.unag. }}$ - Np.m.ag.48) $\left.=8.82 \%\right)$. Same effect was also noticed for unprinted substrates, while further ageing had negligible impact $\left(\Delta \operatorname{Rmax}_{(\text {Cp.m.ag.48 }- \text { Cp.m.ag.96) }}=1.6 \%\right.$; $\left.\Delta \operatorname{Rmax}_{(\text {Np.m.ag.48. }- \text { Np.m.ag.96) }}=1.76 \%\right)$.

Reflectance spectra in Figure 6 shows that the highest reflectance value is obtained on laboratory reference sample $(\mathrm{N})$ in the blue part of the spectrum before artificial ageing, while with addition of wheat pulp in substrate reflectance values decrease. After artificial ageing treatment changes were noticeable $\left(\Delta \mathrm{Rmax}_{(\text {Np.m.unag.-Np.m.ag.48) }}=8.82 \%\right)$. The result values show that the highest degradation occurs after first 48 hours of artificial ageing for all magenta prints

$\left(\Delta \mathrm{Rmax}_{(1 \mathrm{NWp} . \mathrm{m} . \text { unag.-1NWp.m.ag.48) }}=6.45 \%\right.$;

$\Delta \operatorname{Rmax}_{(2 N W \text { p.m.unag.-2NWp.m.ag. } 48)}=4.98 \%$;

$\left.\Delta \operatorname{Rmax}_{(1 \mathrm{NWp} \text {.m.unag.-1NWp.m.ag.48) }}=4.56 \%\right)$, while reflectance values change slightly with the second ageing treatment

$\left(\Delta \operatorname{Rmax}_{(1 \mathrm{NWp} . \mathrm{m} .48-1 \mathrm{NWp} . \mathrm{m.ag} .96)}=1.53 \%\right.$;

$\Delta \operatorname{Rmax}_{(2 \mathrm{NWp} . \mathrm{m} .48 .-2 \mathrm{NWp} . \mathrm{m} . \mathrm{gg} .96)}=1.39 \%$;

$\left.\Delta \mathrm{Rmax}_{(1 \mathrm{NWp} . \mathrm{m} .48-1 \mathrm{NW} \text {.m.ag.96) }}=1.56 \%\right)$,

Figures 7-8 show the results of the reflectance spectra measurements in the visible part of the electromagnetic spectrum before (marked as unag.) and after two artificial ageing treatments (marked as ag.48 and ag. 96) for printed substrates with black ink (marked as p.k.).

Black prints on reference and control samples made from recycled wood pulp (commercial and laboratory) present the expected reflectance curves where minor changes in the reflectance values were obtained (Figure 7). The influence of artificial ageing on black prints are negligible

$\left(\Delta \operatorname{Rmax}_{(\text {Cp.k.unag.. - Cp.k.ag.96) }}=-0.64 \%\right.$;

$\left.\Delta \operatorname{Rmax}_{(\text {Np.k.unag.. - Np.k.ag.96) }}=-0.62 \%\right)$. 


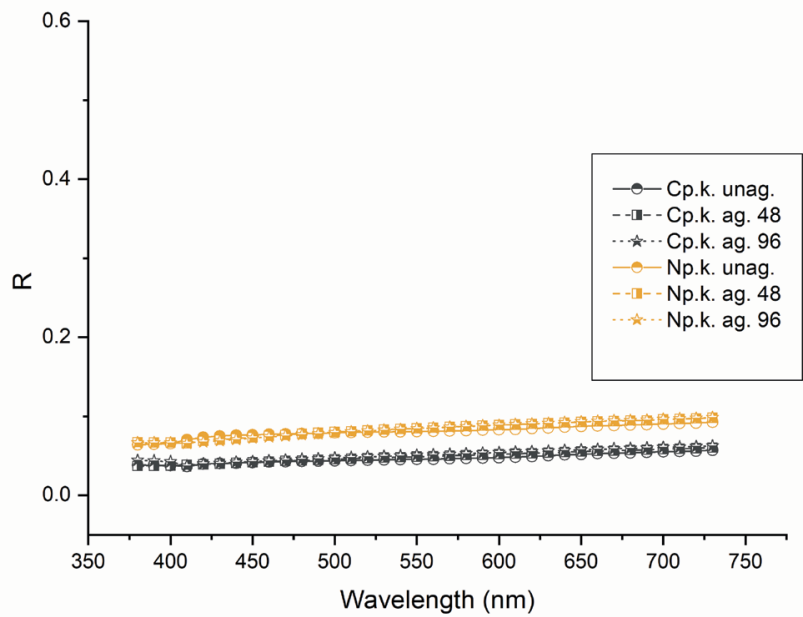

Figure 7: The influence of ageing time on reflectance spectra of control samples -commercial (C) and laboratory $(\mathrm{N})$ printed with black ink

From Figure 8 the same behaviour is visible on black prints made on substrates with wheat pulp (1NW, 2NW, 3NW). All black prints are extremely stable

$\left(\Delta \mathrm{Rmax}_{(1 \mathrm{NWp} . \text { k.unag..-1NWp.k.ag.96) }}=0,51 \%\right.$;

$\Delta \operatorname{Rmax}_{(2 \mathrm{NWp} . \text { k.unag..-1NWp.k.ag.96) }}=1.2 \%$;

$\left.\Delta \operatorname{Rmax}_{(3 N W \text { p.k.unag.. }-3 \text { NWp.k.ag.96) }}=0.28 \%\right)$.

\subsection{Euclidean difference $\left(\Delta E_{00}{ }^{*}\right)$ values}

The highest colour difference is perceived on the unprinted laboratory reference sample made only from recycled wood pulp without wheat pulp (N) after 48 and 96 hours of artificial ageing, while laboratory substrates with addition of wheat pulp from $10 \%$ to $30 \%$ (1NW, 2NW, 3NW) show the lowest values of Euclidean colour difference (Table 5).

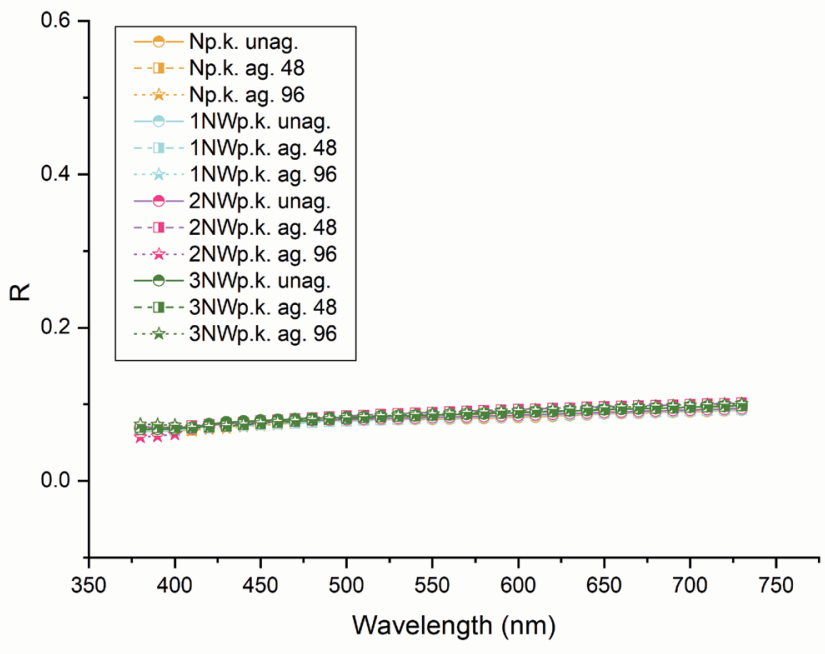

Figure 8: The influence of ageing time on reflectance spectra of black prints made on laboratory substrates without $(\mathrm{N})$ and with wheat pulp (1NW, 2NW, 3NW)

The first cycle of ageing treatment (48 hours) has the highest impact on colorimetric values $\left(\mathrm{L}^{*} \mathrm{a}^{*} \mathrm{~b}^{*}\right)$ of unprinted substrates and substrates printed with magenta ink.

It is also visible that both magenta printed samples $(C, N)$ have shown the highest value of Euclidean colour difference after 48 and 96 hours of artificial ageing, which the average human eye could perceive as a great difference in colour $\left(\Delta \mathrm{E}_{00}{ }^{*}>5\right)$.

The slightest colour changes are obtained on all black prints on substrates with and without wheat pulp after first and second cycle of artificial ageing, which the average observer could notice as a very small difference in colour $\left(\Delta \mathrm{E}_{00}^{*}<2\right)$.

Table 5: Euclidean colour difference $\left(\Delta E_{00}{ }^{*}\right)$ between unaged and aged substrates (unprinted and printed)

\begin{tabular}{|c|c|c|c|c|c|c|}
\hline & \multicolumn{6}{|c|}{ Euclidean colour difference values $\left(\Delta E_{00}{ }^{*}\right)$} \\
\hline & \multicolumn{3}{|c|}{48 hours } & \multicolumn{3}{|c|}{96 hours } \\
\hline & \multirow{2}{*}{ Unprinted } & \multicolumn{2}{|c|}{ Printed } & \multirow{2}{*}{ Unprinted } & \multicolumn{2}{|c|}{ Printed } \\
\hline & & Magenta & Black & & Magenta & Black \\
\hline$C$ & 6.96 & 5.28 & 1.41 & 8.66 & 6.30 & 1.86 \\
\hline$N$ & 8.13 & 5.08 & 2.21 & 9.04 & 6.44 & 2.41 \\
\hline $1 N W$ & 6.56 & 3.77 & 0.83 & 7.23 & 4.88 & 1.34 \\
\hline $2 N W$ & 3.70 & 3.42 & 1.76 & 5.18 & 4.36 & 1.77 \\
\hline $3 N W$ & 4.39 & 3.35 & 1.06 & 4.84 & 4.07 & 1.25 \\
\hline
\end{tabular}




\section{Conclusions}

The main goal of this research was to determine the influence of different proportions of straw pulp in laboratory substrates printed by digital UV inkjet printing technique on optical stability during artificial ageing.

Considering all the results obtained, the following could be concluded:

- The highest colour degradation of prints occurs in the first 48 hours of artificial ageing for all samples.

- Black ink provides prints with higher optical stability regardless of the printing substrate composition.

- Addition of wheat pulp in printing substrate positively affects the optical stability of all analysed digital printed laboratory substrates.

The obtained results of the optical stability of unprinted and printed substrates in this research indicate that addition of wheat pulp could additionally improve properties of paper as a printing substrate.

\section{Acknowledgements}

This work has been supported in part by Croatian Science Foundation under the project „Printability, quality and utilization of substrates with non-wood fibres" (UIP-201705-2573).

\section{References}

1. Zervos S. Natural and Accelerated Ageing of Cellulose and Paper: A Literature Review. In: Cellulose: Structure and Properties, Derivatives and Industrial Uses, Lejeune A. and Deprez T.,editors, New York, Nova Science Publishers Inc, Hauppauge; 2010. p. 155-203.

2. Bates I, Plazonić I, Radić Seleš V, Barbarić-Mikočević Ž. Determining the quality of paper substrates containing triticale pulp for printing industry. Nordic Pulp \& Paper Research Journal, 2020, 35(2): 272-278. doi:https://.org/10.1515/npprj-2020-0009

3. Cabalova I, Kacik F, Geffert A, Kacikova D. The Effects of Paper Recycling and its Environmental Impact. Chapters, in: Elzbieta Broniewicz (ed.), Environmental Management in Practice, IntechOpen. DOI: 10.5772/23110 Available from: https://www.intechopen.com/books/environmentalmanagement-in-practice/the-effects-of-paperrecycling-and-its-environmental-impact

4. Blanco A, Miranda R, Concepcion Monte M. Extending the limits of paper recycling: Improvements along the paper value chain, Forest Systems,2013; 22(3):471-483, DOI: $\underline{10.5424 /}$ fs/2013223-03677

5. Fang G, Shen K. Wheat Straw Pulping for Paper and Paperboard Production. Chapter 12 in Global Wheat Production, Intech Open, (2018) Shah Fahad (ed.), pp. 223-239. DOI: 10.5772/intechopen.72559, ISBN 978-1-78923-337-7, Print ISBN: 978-1-78923-336-0

6. Plazonic I, Bates I, Barbaric-Mikocevic Z. The Effect of Straw Fibres in Printing Papers on Dot Reproduction Attributes, as Realized by UV Inkjet Technology. BioResources, 2016; 11(2): 5033-5049.

7. Roberts $S$. The potential of the non-wood fibre paper sector. IIED Sub-Study No. 7, 1996. p.63, ISBN: 9781843691532 Available from: https://pubs.iied. org/8068IIED

8. Chandra M. Use of non-wood plant fibers for pulp and paper industry in Asia: Potential in China. Master'sdegree thesis, Virginia Polytechnic Institute and State University, Blacksburg, Virginia, USA, 1998. p. 91

9. Area M-C, Cheradame H. Paper ageing and degradation: recent findings and research methods. BioResources, 2011; 6(4):5307-5337.

10. Thompson B. Printing Materials: Science and Technology. Pira International, Leatherhead, Surrey, United Kingdom 2004. 
Determining the optical stability of printed laboratory substrates with wheat pulp after ageing treatment

11. Havlinova B, Babiakova D, Brezova V, Durovič M, Novotna M, Belanyi F. The stability of offset inks on paper upon ageing. Dyes and Pigments, 2002; B. 54: 173-188.

12. Pauler N. Paper Optics - Optical and colour science related to the pulp and paper industry", $\mathrm{AB}$ Lorentzen \& Wettre, Sweden, 2012.

13. Bates I, Plazonić I, Petric Maretić K, Rudolf M, Radić Seleš V.: Measurement of the ink penetration into laboratory papers with wheat pulp and its influence on print quality, Proceedings of 3rd International Printing Technologies Symposium Istanbul Turkey (2019) Oktav M, Akgül A, Oğuz M, Özdemir L,
Özomay Z, Sesli Y. (ed.), pp. 287-295 Istanbul,

Turkey: Printing Industry Education Foundation

14. Kipphan H. Handbook of Print Media: Technologies and Production Methods. Springer, Berlin, 2001.

15. ASTM D 6789-02, Test Method for Accelerated Light Ageing of Printing and Writing Paper by Xenon-Arc Exposure Apparatus (2002).

16. Luo M.R, Cui G, Rigg B. The development of the CIE 2000 colour difference formula: CIEDE2000. Color Research \& Application, 2001; 26: 340 -350.

17. Zjakić I. Upravljanje kvalitetom ofsetnog tiska, Hrvatska sveučilišna naklada, Zagreb, 2007 